\title{
Expression of excision repair cross-complementation group 1 and class III $\beta$-tubulin in thymic carcinoma
}

\author{
KATSUHIRO OKUDA, RISA ODA, AYUMI SUZUKI, TSUTOMU TATEMATSU, \\ HIROSHI HANEDA, SATORU MORIYAMA, MOTOKI YANO and RYOICHI NAKANISHI
}

Department of Oncology, Immunology and Surgery, Nagoya City University Graduate School of Medical Sciences, Nagoya 467-8601, Japan

Received June 11, 2015; Accepted February 27, 2017

DOI: $10.3892 / \mathrm{ol} .2017 .5805$

\begin{abstract}
Thymic carcinoma is a rare mediastinum malignant tumor derived from thymic epithelial cells. With the exception of complete resection, an effective therapy has not been established to date for advanced or relapsed thymic carcinoma. The present study examined the protein expression of excision repair cross-complementation group 1 (ERCC1) and class III $\beta$-tubulin (TUBB3), which are consider to be indicators of the anticancer activity of platinum-based and taxane-based chemotherapy, respectively. The expression of ERCC1 and TUBB3 proteins was examined in 40 thymic carcinoma patients who underwent either surgical resection or core-needle biopsy. The present study investigated whether the expression of ERCC1 and TUBB3 proteins was associated with the overall survival and clinicopathological factors of thymic carcinoma patients. The expression of ERCC1 and TUBB3 proteins was also evaluated in 50 patients who underwent curative resection for non-small cell lung cancer (NSCLC). The expression of ERCC1 and TUBB3 proteins was positive in 8 cases $(20 \%)$ among the thymic carcinoma patients. ERCC1 was expressed in 21 cases (42\%), while TUBB3 was expressed in 27 cases (54\%), among the 50 NSCLC patients evaluated in the present study. Only complete resection was observed to be associated with a better prognosis than incomplete resection $(\mathrm{P}=0.0341)$. Other clinicopathological factors, including expression of ERCC1 and TUBB3 proteins, exhibited no effect on overall survival. The expression of ERCC1 and TUBB3 proteins in the thymic carcinoma cases was lower than that in the NSCLC cases. The present results suggest a possibility for
\end{abstract}

Correspondence to: Dr Katsuhiro Okuda, Department of Oncology, Immunology and Surgery, Nagoya City University Graduate School of Medical Science, 1 Kawasumi, Mizuho-cho, Mizuho-ku, Nagoya 467-8601, Japan

E-mail:kokuda@med.nagoya-cu.ac.jp

Key words: thymic carcinoma, excision repair cross-complementation group 1 , class III $\beta$-tubulin, platinum-based chemotherapy, taxane-based chemotherapy better antitumor effects of platinum-based and taxane-based chemotherapy on thymic carcinoma patients.

\section{Introduction}

Thymic carcinoma is a rare and invasive mediastinum neoplasm. The frequency of thymic carcinoma is higher in Asian than in Caucasian populations (1). It is difficult to detect these type of tumors in the early stage, since the symptoms of the disease are not remarkable until it invades or compromises other organs, including the heart, nerves, bronchus and blood vessels $(2,3)$. The most favorable treatment is complete surgical resection $(2,3)$; however, the majority of thymic carcinomas already invade into other organs and are metastasized when they are detected (4-6). For advanced and relapsed thymic carcinoma cases, no optimal chemotherapeutic drug or regimen exists. Previous studies on chemotherapy for advanced thymic carcinoma, which were based on the regimens used for advanced thymoma, lung cancer and germ cell tumors, employed cisplatin-based chemotherapy (7-10). Furthermore, second-line chemotherapy regimen has not been established. To establish the effective regimens for thymic carcinoma, only small-scale clinical trials have been conducted to date based on a single case report (11-14). Therefore, an effective and safe drug regimen for advanced and relapsed thymic carcinoma must be identified.

Clinical trials for thymic carcinoma are difficult due to its rareness. To solve this problem, the present study aimed to evaluate thymic cancer patients retrospectively. In order to examine the predictive factors of the chemotherapeutic agent, the expression of excision repair cross-complementation group 1 (ERCC1) and class III $\beta$-tubulin (TUBB3) proteins was investigated by immunohistochemistry (IHC) in thymic carcinoma specimens. Previous studies reported that ERCC1 disturbs platinum-based chemotherapy (15-17), while TUBB3 disturbs taxane-based chemotherapy (18-20). Our group previously demonstrated that completely resected non-small cell lung cancer (NSCLC) patients, whose tumors were negative for ERCC1 and TUBB3 expression by IHC, exhibited better prognosis upon receiving platinum-based plus paclitaxel chemotherapy than patients whose tumors were positive for ERCC1 and TUBB3 expression according to IHC (21). The present study is a retrospective follow-up 
study that evaluates the protein expression and effectiveness of carboplatin plus paclitaxel (CP) chemotherapy for thymic carcinoma patients.

\section{Patients and methods}

Patients. The present study examined the expression of ERCC1 and TUBB3 proteins in 40 thymic carcinoma patients who underwent either surgical resection or core-needle biopsy from June 1986 to November 2012 at Nagoya City University Hospital (Nagoya, Japan). The expression of ERCC1 and TUBB3 proteins was also evaluated in 50 patients who underwent curative resection for NSCLC. The present study was approved by the Institutional Review Board of Nagoya City University Hospital, and all the patients consented to the use of their tissues for the present analysis.

Among these patients, 1 was in Masaoka stage I (2.5\%), 8 in stage II (20.0\%), 9 in stage III (22.5\%), 7 in stage IVA $(17.5 \%)$ and 15 in stage IVB (37.5\%) of the disease (22). The clinical and pathological characteristics of these 40 thymic carcinoma patients are as follows: $24(60.0 \%)$ patients were male and $16(40.0 \%)$ were female. In total, 31 patients $(77.5 \%)$ were diagnosed as squamous cell carcinoma, $5(12.5 \%)$ as neuroendocrine carcinoma (NET), $3(7.5 \%)$ as adenocarcinoma and $1(2.5 \%)$ as mucoepidermoid carcinoma. A total of 15 patients were treated with complete surgical resection, 9 with incomplete surgical resection and 16 with biopsy. For all patients, the median overall survival was 73 months. The present study investigated whether the expression of ERCC1 and TUBB3 proteins was associated with the overall survival and clinicopathological factors of thymic carcinoma patients.

IHC staining. The same IHC method and evaluation for ERCC1 and TUBB3 as that reported in our previous study on lung cancer patients was used in the present study (21). The antibody against ERCC1 was an anti-ERCC1 mouse monoclonal antibody (clone 8F1; Abcam, Cambridge, UK). The proportion score of tumor nuclear staining intensity (0-3) was multiplied by the staining intensity of nuclei ( 0 if $0 \%$; 0.1 if $1-9 \%$; 0.5 if $10-49 \%$; and 1.0 if $\geq 50 \%$ ) in order to obtain a final semiquantitative H-score. An ERCC1 IHC score of $\geq 1.0$ was considered as positive (Fig. 1A).

The antibody against TUBB3 was an anti-class III $\beta$-tubulin monoclonal antibody (clone TUJ1; Covance, Inc., Princeton, NJ, USA). Over $50 \%$ of positive cells with a staining intensity of 2 was considered as TUBB3 positive (Fig. 1B).

Statistical analysis. Survival curves were generated using the Kaplan-Meier method, and the log-rank test was used to assess the statistical significance of the differences between groups. The Cox proportional hazards model was used to estimate the hazard ratios and $95 \%$ confidence intervals (CIs). Prognostic variables identified by univariate analysis were further analyzed in a multivariate Cox model. Of note, the analysis of the present study had limitations in terms of interpretation due to the small number of patients. Two-sided $\mathrm{P}<0.05$ was considered to indicate a statistically significant difference. All data were analyzed with EZR software version 1.33 (http://www.jichi.ac.jp/saitama-sct/SaitamaHP. files/statmedEN.html) (23).
A

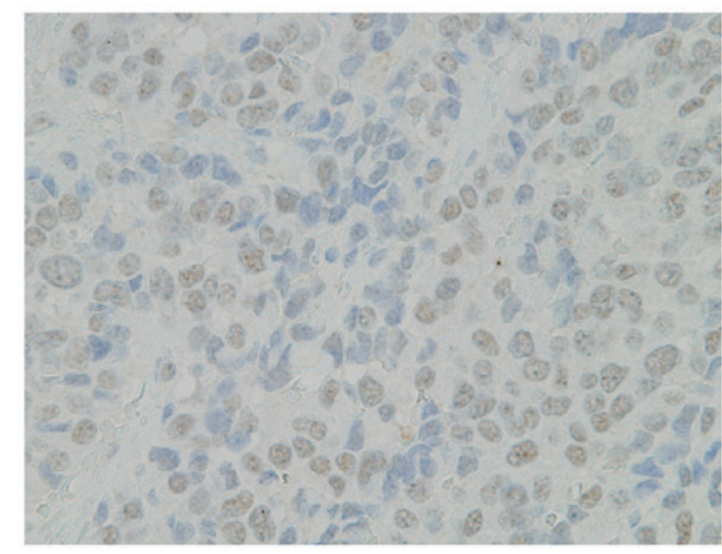

B

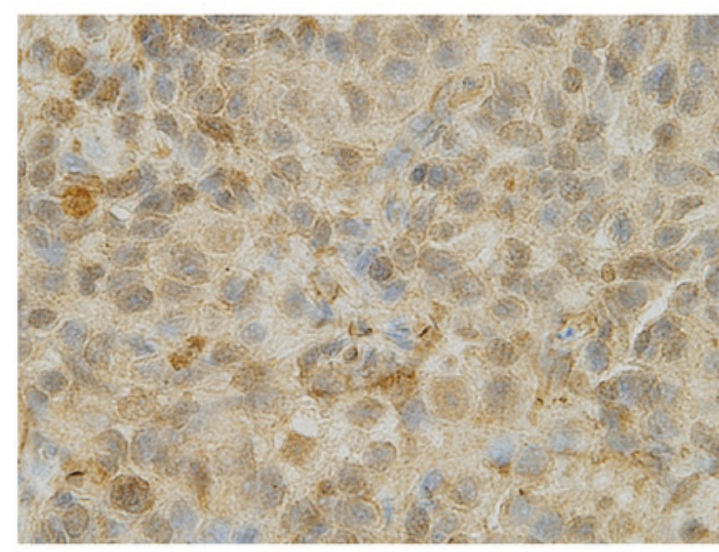

Figure 1. Immunohistochemistry of thymic carcinoma patients. (A) Excision repair cross-complementation group 1-positive case. (B) Class III $\beta$-tubulin-positive case. Magnification, $\mathrm{x} 400$.

\section{Results}

ERCC1 expression in 40 thymic carcinoma and 50 NSCLC patients. ERCC1 IHC staining was negative in 32/40 cases $(80 \%)$ of thymic carcinoma. Only $8 / 40$ cases $(20 \%)$ were positive for ERCC1 IHC staining. No association between the expression of ERCC1 and clinicopathological factors was identified (Table I). The expression of ERCC1 was examined by IHC in 50 NSCLC patients who underwent curative resection in order to compare the expression of the ERCC1 protein between thymic carcinoma and NSCLC patients. The results revealed that 29 cases $(58 \%)$ were negative and 21 cases $(42 \%)$ were positive for ERCC1 IHC staining.

TUBB3 expression in 40 thymic carcinoma and 50 NSCLC patients. TUBB3 IHC staining was negative in 32/40 cases (80\%) of thymic carcinoma. Only 8/40 cases (20\%) were positive for TUBB3 IHC staining. No association was observed between the expression of TUBB3 and clinicopathological factors, including ERCC1 IHC staining (Table II). In order to compare the expression of the TUBB3 protein between thymic carcinoma and NSCLC patients, TUBB3 protein expression was examined by IHC in 50 NSCLC patients who underwent curative resection. The results revealed that 23 cases $(46 \%)$ were negative and 27 (54\%) positive for TUBB3 IHC staining.

Factors associated with the overall survival of 40 thymic carcinoma patients. In all 40 cases, the 3 -year overall survival 
Table I. Patients' characteristics according to ERCC1 expression.

\begin{tabular}{lcccc}
\hline & & \multicolumn{2}{c}{ ERCC1 expression } & \\
\cline { 3 - 4 } Characteristic & No. & $\begin{array}{c}\text { Negative } \\
(\mathrm{n}=32)\end{array}$ & $\begin{array}{c}\text { Positive } \\
(\mathrm{n}=8)\end{array}$ & P-value \\
\hline Age (years) & & & & 0.3821 \\
$>60$ & 22 & 16 & 6 & \\
$\leq 60$ & 18 & 16 & 2 & 0.8087 \\
Sex & & & & \\
$\quad$ Male & 24 & 19 & 5 & 0.7764 \\
Female & 16 & 13 & 3 & \\
Histology & & & & \\
SCC & 31 & 25 & 6 & \\
$\quad$ Others & 9 & 7 & 2 & \\
Masaoka stage & & & 3 & \\
IVA, IVB & 22 & 19 & 3 & \\
I-III & 18 & 13 & 5 & \\
\hline
\end{tabular}

ERCC1, excision repair cross-complementation group 1; SCC, squamous cell carcinoma.

Table II. Patients' characteristics according to TUBB3 expression.

\begin{tabular}{|c|c|c|c|c|}
\hline \multirow[b]{2}{*}{ Characteristic } & \multirow[b]{2}{*}{ No. } & \multicolumn{2}{|c|}{ TUBB3 expression } & \multirow[b]{2}{*}{ P-value } \\
\hline & & $\begin{array}{c}\text { Negative } \\
(\mathrm{n}=32)\end{array}$ & $\begin{array}{c}\text { Positive } \\
(\mathrm{n}=8)\end{array}$ & \\
\hline Age (years) & & & & 0.9367 \\
\hline$>60$ & 22 & 17 & 5 & \\
\hline$\leq 60$ & 18 & 15 & 3 & \\
\hline Sex & & & & 0.2942 \\
\hline Male & 24 & 21 & 3 & \\
\hline Female & 16 & 11 & 5 & \\
\hline Histology & & & & 0.1076 \\
\hline $\mathrm{SCC}$ & 31 & 27 & 4 & \\
\hline Others & 9 & 5 & 4 & \\
\hline Masaoka stage & & & & 0.9367 \\
\hline IVA, IVB & 22 & 18 & 4 & \\
\hline I-III & 18 & 14 & 4 & \\
\hline $\begin{array}{l}\text { ERCC1 } \\
\text { expression }\end{array}$ & & & & 0.3738 \\
\hline Positive & 8 & 6 & 2 & \\
\hline Negative & 32 & 26 & 6 & \\
\hline
\end{tabular}

ERCC1, excision repair cross-complementation group 1; TUBB3, class III $\beta$-tubulin; SCC, squamous cell carcinoma.

rate was $67.3 \%$ (Fig. 2A). Only complete resection was associated with a better prognosis ) than incomplete resection ( $\mathrm{P}=0.0341$; Fig. 2B). Other clinicopathological factors,
Table III. Factors associated with overall survival of 40 thymic carcinoma patients.

\begin{tabular}{|c|c|c|c|}
\hline \multirow[b]{2}{*}{ Characteristic } & \multicolumn{3}{|c|}{ 3-year survival } \\
\hline & No. & $\%$ & P-value \\
\hline Age (years) & & & 0.106 \\
\hline$>60$ & 22 & 77.2 & \\
\hline$\leq 60$ & 18 & 56.9 & \\
\hline Sex & & & 0.707 \\
\hline Male & 24 & 67.8 & \\
\hline Female & 16 & 68.2 & \\
\hline Histology & & & 0.362 \\
\hline $\mathrm{SCC}$ & 31 & 65.7 & \\
\hline Others & 9 & 72.9 & \\
\hline Masaoka stage & & & 0.767 \\
\hline IVA, IVB & 22 & 73.2 & \\
\hline I-III & 18 & 60.0 & \\
\hline Complete resection & & & 0.0341 \\
\hline R0 & 15 & 91.7 & \\
\hline R1, R2 & 25 & 58.4 & \\
\hline ERCC1 expression & & & 0.823 \\
\hline Positive & 8 & 60.0 & \\
\hline Negative & 32 & 68.0 & \\
\hline $\begin{array}{l}\text { Class III } \beta \text {-tubulin } \\
\text { expression }\end{array}$ & & & 0.125 \\
\hline Positive & 8 & 45.0 & \\
\hline Negative & 32 & 73.3 & \\
\hline
\end{tabular}

${ }^{a}$ Univariate analysis using the log-rank test. ERCC1, excision repair cross-complementation group 1; SCC, squamous cell carcinoma.

including the expression of ERCC1 and TUBB3 proteins, had no effect on overall survival (Table III). The expression of ERCC1 or TUBB3 proteins did not affect overall survival (Fig. 2C and D).

Clinicopathological features of 19 patients with thymic carcinoma who received platinum-based chemotherapy (first treatment). The response rate of platinum-based chemotherapy was $52.6 \%$ ( 10 out of 19 cases). Among 16 cases who received platinum-based plus paclitaxel chemotherapy, the response rate was 56.3\% (9 out of 16 cases). Among the 11 patients who were negative for both ERCC1 and TUBB3 expression, the response rate was $63.6 \%$ ( 7 out of 11 cases) (Table IV).

Clinicopathological features of 13 patients with ERCCl and/ or TUBB3 IHC-positive expression. In the ERCC1-positive cases, there was neither partial response (PR) nor complete response for platinum-based chemotherapy. Tissues of NET were positive for TUBB3 (all 4 cases). However, in the squamous cell carcinoma cases of TUBB3-positive and ERCC1-negative expression, $\mathrm{CP}$ chemotherapy was effective in 2 out of 3 patients, thereby achieving PR. 


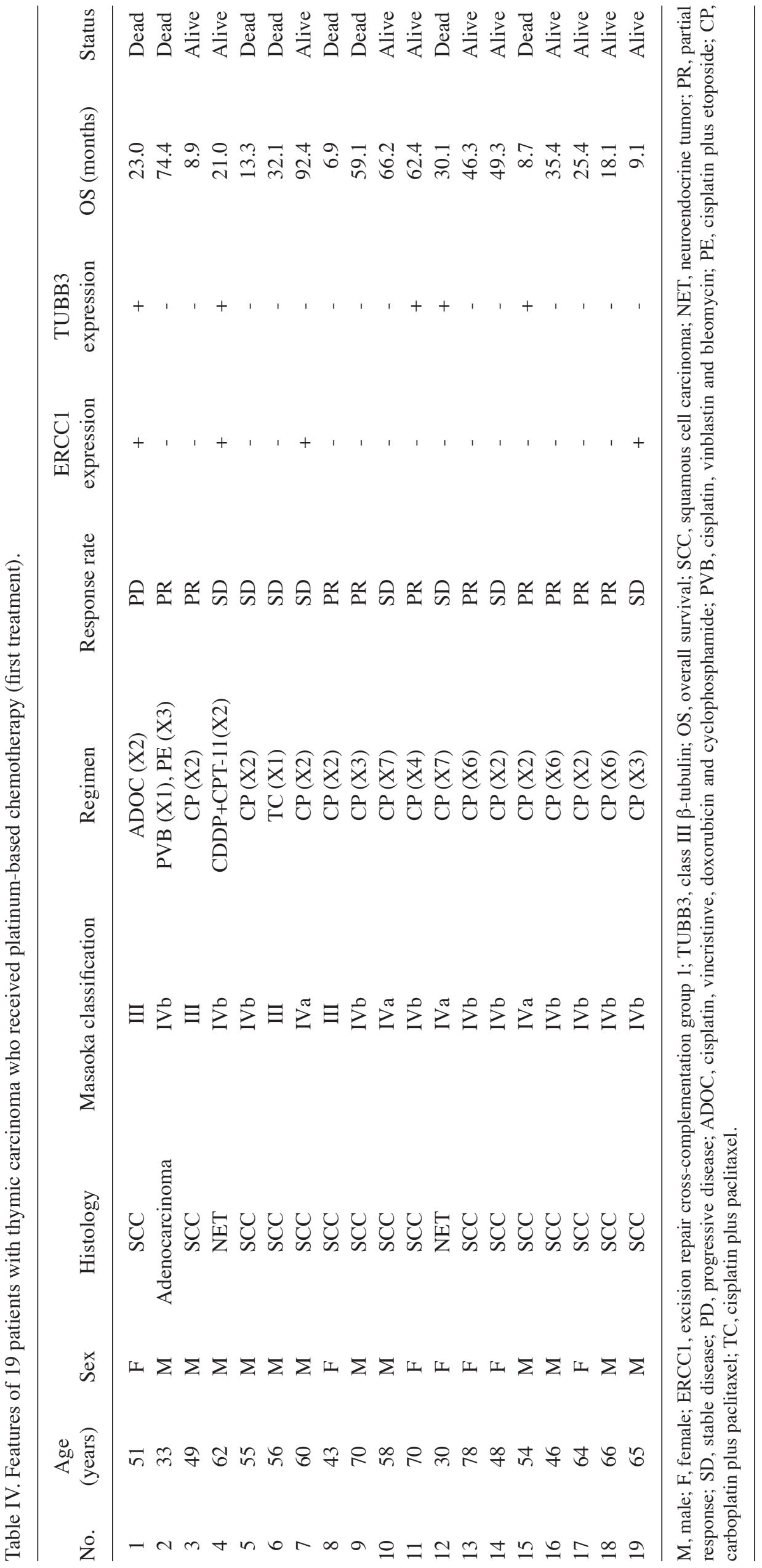


A

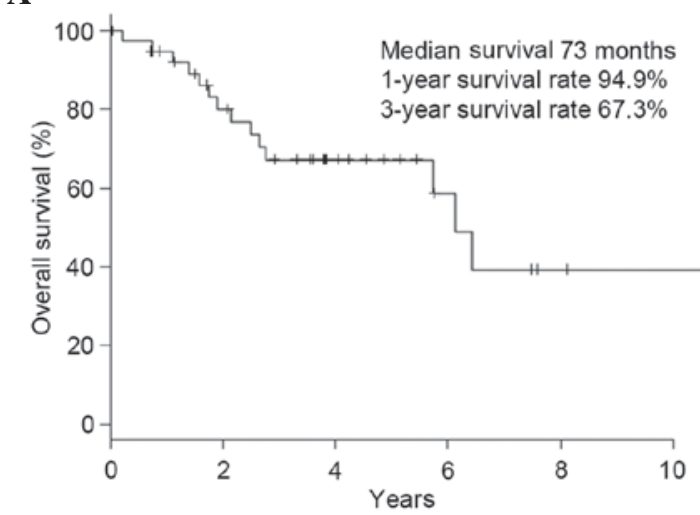

C

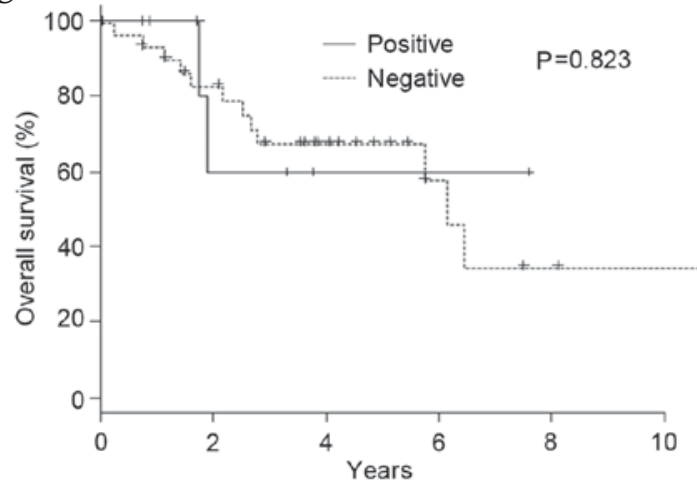

B

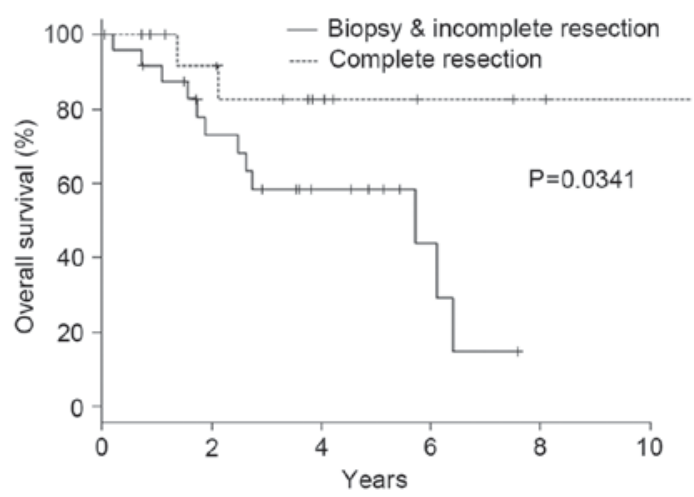

D

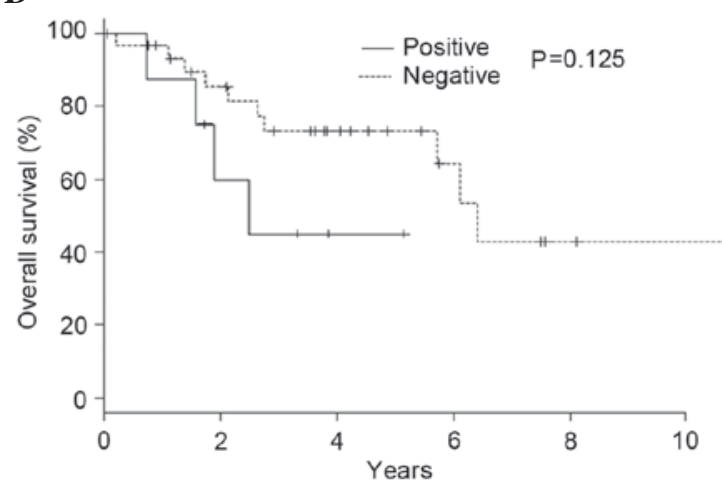

Figure 2. Kaplan-Meier estimate of overall survival. (A) Overall survival of 40 thymic carcinoma patients. (B) Overall survival according to resectability. (C) Overall survival according to the expression of excision repair cross-complementation group 1 protein. (D) Overall survival according to the expression of class III $\beta$-tubulin protein.

Expression of ERCC1 and TUBB3 proteins among 50 NSCLC patients. ERCC1 expression was observed to be positive in 21 cases $(42 \%)$, and TUBB3 expression was positive in 27 cases (54\%).

\section{Discussion}

Thymic carcinoma is a rare and invasive mediastinum malignant tumor. It is urgent to identify an improved treatment for advanced and relapsed thymic carcinoma patients, since no optimal treatment has been established so far. Recently, platinum-based plus taxane-based chemotherapies are considered the standard regimens for the treatment of lung cancer patients $(24,25)$. CP chemotherapy is another regimen for thymic malignant tumors, thymic carcinomas and thymomas. To a certain degree, case reports and small-size clinical trials reported the effectiveness of $\mathrm{CP}$ regimens for thymic malignant tumors (26-29). However, one of the remarkable problems in those previous studies was that they examined thymic epithelial malignant tumors without separating them from thymic carcinoma and thymoma. Thymic carcinoma and thymoma should be distinguished, as they exhibit different biological symptoms (30). The reaction towards chemotherapy, prognosis and metastatic form are different in each tumor type. In the present study, the expression of ERCC1 and TUBB3 proteins was examined in 40 thymic carcinoma patients in order to clarify whether the expression of these proteins was associated with prognosis and clinicopathological factors.
Among the NSCLC patients who received platinum-based plus taxane-based chemotherapies (mainly $\mathrm{CP}$ ), the chemotherapy was effective for all patients, with the exception of those who exhibited overexpression of ERCC1 and TUBB3 proteins. According to a previous large-scale study on lung cancer patients, the overexpression of ERCC1 and TUBB3 proteins appeared to be associated with resistance to platinum-based and taxane-based chemotherapies (15-21). The present study aimed to study the expression of ERCC1 and TUBB3 proteins in thymic carcinoma patients. Collecting a large number of patients' tissues (including those who received platinum-based and taxane-based chemotherapies in order to examine the effect of therapy) was difficult, as well as interpreting the results of IHC, due to the limited number of thymic carcinoma cases, since this tumor is rare. The present study also examined the expression of ERCC1 and TUBB3 proteins among 50 NSCLC patients in order to compare the protein expression ratio. The expression of ERCC1 and TUBB3 proteins determined by IHC was compared between thymic carcinoma and lung cancer patients by using the absolute scoring assessment and the same immunostaining method as previously reported (21). The expression of ERCC1 and TUBB3 proteins in the thymic carcinoma cases were lower than those in the NSCLC cases. In addition, $\mathrm{CP}$ chemotherapy was also observed to be effective for thymic carcinoma. The IHC results for ERCC1 and TUBB3 may help to select the best chemotherapy regimen for thymic carcinoma patients.

In the current study, the expression of ERCC1 and TUBB3 proteins in the thymic carcinoma cases were lower than those 
in the NSCLC cases. As a result of examining NSCLC patients who received cisplatin-based chemotherapy (mainly $\mathrm{CP}$ ), it was observed that chemotherapy was effective for all patients, with the exception of those overexpressing ERCC1 and TUBB3. The overexpression of ERCC1 and TUBB3 appeared to be associated with resistance to platinum- and taxane-based chemotherapies. These results indicated that platinum-based plus taxane-based regimens, which are two of the standard treatments for NSCLC, may be effective for the treatment of thymic carcinoma patients. Therefore, platinum-based plus taxane-based regimens should be considered as standard regimens for thymic cancer patients.

The present study also investigated the effect of platinum-based chemotherapy and the $\mathrm{CP}$ regimen in 19 thymic carcinoma patients (including those receiving advanced and neo-adjuvant chemotherapy). The response rate to the platinum-based chemotherapy was $52.6 \%$. Limited to the patients who were negative for both ERCC1 and TUBB3 and received the CP regimen, the response rate was $63.6 \%$. For the ERCC1-positive cases, more effective regimens were identified without using the platinum-based drug. Since the TUBB3-positive cases, including NET cases, exhibited resistance to taxane-based chemotherapy, chemotherapy regimens used in small cell lung cancer may be effective for those cases.

Kaira et al (31) reported the analysis of ERCC1 and TUBB3 expression in thymic epithelial tumors, including 39 thymomas and 17 thymic carcinomas. The authors concluded that ERCC1 and TUBB3 expression may be associated with resistance to $\mathrm{CP}$ regimen, in agreement with the present findings.

Due to its rare frequency, it is difficult to plan clinical trials for thymic carcinoma patients. Yet, a prospective, worldwide, randomized, controlled trial of chemotherapy for advanced and relapsed thymic carcinoma is required.

The present study examined the expression levels of ERCC1 and TUBB3 proteins, and identified that CP chemotherapy is effective for thymic carcinoma patients. The results of the present study also indicated that ERCC1 and TUBB3 expression could serve as biomarkers that may help to identify the subgroup of thymic carcinoma patients likely to benefit from platinum-based and taxane-based chemotherapies.

\section{References}

1. Shimosato Y, Kameya T, Ngai K and Suemasu K: Squamous cell carcinoma of the thymus. An analysis of eight cases. Am J Surg Pathol 1: 109-121, 1977.

2. Weksler B, Dhupar R, Parikh V, Nason KS, Pennathur A and Ferson PF: Thymic carcinoma: A multivariate analysis of factors predictive of survival in 290 patients. Ann Thorac Surg 95: 299-303, 2013.

3. Zhao Y,Zhao H, Hu D, Fan L, Shi J and Fang W: Surgical treatment and prognosis of thymic squamous cell carcinoma: A retrospective analysis of 105 cases. Ann Thorac Surg 96: 1019-1024, 2013.

4. Suster S and Rosai J: Thymic carcinoma. A clinicopathologic study of 60 cases. Cancer 67: 1025-1032, 1991

5. Hsu CP, Chen CY, Chen CL, Lin CT, Hsu NY, Wang JH and Wang PY: Thymic carcinoma. Ten year' experience in twenty patients. J Thorac Cardiovasc Surg 107: 615-620, 1994.

6. Takeda S, Sawabata N, Inoue M, Koma M, Maeda H and Hirano H: Thymic carcinoma. Clinical institutional experience with 15 patients. Eur J Cardiothorac Surg 26: 401-406, 2004.

7. Agatsuma T, Koizumi T, Kanda S, Ito M, Urushihata K, Yamamoto H, Hanaoka M and Kubo K: Combination chemotherapy with doxorubicin, vincristine, cyclophosphamide, and platinum compounds for advanced thymic carcinoma. J Thorac Oncol 6: 2130-2134, 2011.
8. Yoh K, Goto K, Ishii G, Niho S, Ohmatsu H, Kubota K, Kakinuma R, Nagai K, Suga M and Nishiwaki Y: Weekly chemotherapy with cisplatin, vincristine, doxorubicin, and etoposide is an effective treatment for advanced thymic carcinoma. Cancer 98: 926-931, 2003.

9. Okuma Y, Hosomi Y, Takagi Y, Iguchi M, Okamura T and Shibuya M: Cisplatin and irinotecan combination chemotherapy for advanced thymic carcinoma: Evaluation of efficacy and toxicity. Lung Cancer 74: 492-496, 2011.

10. Magois E, Guigay J, Blancard PS, Margery J, Milleron B, Lher P and Jounieaux V: Multimodal treatment of thymic carcinoma: Report of nine cases. Lung Cancer 59: 126-132, 2008.

11. Oguri T, Achiwa H, Kato D, Maeda H, Niimi T, Sato S and Ueda R: Efficacy of docetaxel as a second-line chemotherapy for thymic carcinoma. Chemotherapy 50: 279-282, 2004.

12. Liang Y, Padda SK, Piess JW, West RB, Neal JW and Wakelee HA: Pemetrexed in patients with thymic malignancies previously treated with chemotherapy. Lung Cancer 87: 34-38, 2015.

13. Okuma Y, Shimokawa T, Takagi Y, Hosomi Y, Iguchi M, Okamura T and Shibuya M: S-1 is an acrive anticancer agent for advanced thymic carcinoma. Lung Cancer 70: 357-363, 2010.

14. Tagawa T, Ohta M, Kuwata T, Awaya H and Ishida T: S-1 plus cisplatin chemotherapy with concurrent radiation for thymic basaloid carcinoma. J Thorac Oncol 5: 572-573, 2010.

15. Altaha R, Liang X, Yu JJ and Reed E: Excision repair cross complementing-group 1: Gene expression and platinum resistance. Int J Mol Med 14: 959-970, 2004.

16. Lord RV, Brabender J, Gandara D, Alberola V, Camps C, Domine M, Cardenal F, Sánchez JM, Gumerlock PH, Tarón M, et al: Low ERCC1 expression correlates with prolonged survival after cisplatin plus gemcitabine chemotherapy in non-small cell lung cancer. Clin Cancer Res 8: 2286-2291, 2002.

17. Metzger R, Leichman CG, Danenberg KD, Danenberg PV, Lenz HJ, Hayashi K, Groshen S, Salonga D, Cohen H, Laine L, et al: ERCC1 mRNA levels complement thymidylate synthase mRNA levels in predicting response and survival for gastric cancer patients receiving combination cisplatin and fluorouracil chemotherapy. J Clin Oncol 16: 309-316, 1998.

18. Katsetos CD, Legido A, Perentes E and Mörk SJ: Class III beta-bululin isotype: A key cytoskeletal protein at the crossroads of developmental neurobiology and tumor neuropathology. J Child Neurol 18: 851-866, discussion 867, 2003.

19. Lu Q and Luduena RF: Removal of beta III isotype enhances taxol induced microtubule assembly. Cell Struct Funct 18: 173-182, 1993.

20. Kamath K, Wilson L, Cabral F and Jordan MA: BetaIII-tubulin induces paclitaxel resistance in association with reduced effects on microtubule dynamic instability. J Biol Chem 280: 12902-12907, 2005.

21. Okuda K, Sasaki H, Dumontet C, Kawano O, Yukiue H, Yokoyama T, Yano M and Fujii Y: Expression of excision repair cross-complementation group 1 and class III beta-tubulin predict survival after chemotherapy for completely resected non-small cell lung cancer. Lung Cancer 62: 105-112, 2008.

22. Masaoka A, Monden Y, Nakahara K and Tanioka T: Follow-up study of thymomas with special reference to their chlinical stages. Cancer 48: 2485-2492, 1981.

23. Kanda Y: Investigation of the freely available easy-to-use software 'EZR' for medical statistics. Bone Marrow Transplant 48: 452-458, 2013.

24. Schiller JH, Harrington D, Belani CP, Langer C, Sandler A, Krook J, Zhu J and Johnson DH; Eastern Cooperative Oncology Group: Comparison of four chemotherapy regimens for advanced non-small-cell lung cancer. N Engl J Med 346: 92-98 2002.

25. Lilenbaum RC, Herndon JE II, List MA, Desch C, Watson DM, Miller AA, Graziano SL, Perry MC, Saville W, Chahinian P, et al: Single-agent versus combination chemotherapy in advanced non-small-cell lung cancer: The cancer and leukemia group B (study 9730). J Clin Oncol 23: 190-196, 2005.

26. Lemma GL, Lee JW, Aisner SC, Langer CJ, Tester WJ, Johnson DH and Loehrer PJ Sr: Phase II study of carboplatin and paclitaxel in advanced thymoma and thymic carcinoma. J Clin Oncol 29: 2060-2065, 2011.

27. Igawa S, Murakami H, Takahashi T, Nakamura Y, Tsuya A, Naito T, Kaira K, Ono A, Shukuya T, Tamiya A, et al: Efficacy of chemotheraoy with carboplatin and paclitaxel for unresectable thymic carcinoma. Lung Cancer 67: 194-197, 2010. 
28. Furugen M, Sekine I, Tsuta K, Horinouchi H, Nokihara H, Yamamoto N, Kubota K and Tamura T: Combination chemotherapy with carboplatin and paclitaxel for advanced thymic cancer. Jpn J Clin Oncol 41: 1013-1016, 2011.

29. Hirai F, Yamanaka T, Taguchi K, Daga H, Ono A, Tanaka K, Kogure Y, Shimizu J, Kimura T, Fukuoka J, et al: A multicenter phase II study of carboplatin and paclitaxel for advanced thymic carcinoma: WJOG4207L. Ann Oncol 26: 363-368, 2015.
30. Weiss GJ: Thymic carcinoma: Current and future therapeutic interventions. Expert Opin Investig Drugs 19: 1007-1016, 2010.

31. Kaira K, Serizawa M, Koh Y, Miura S, Kaira R, Abe M, Nakagawa K, Ohde Y, Okumura T, Naito T, Murakami H, Takahashi T, Kondo H, Nakajima T, Endo M and Yamamoto N: Expression of excision repair cross-complementation group 1, breast cancer susceptibility 1 , and $\beta$ III-tubulin in thymic epithelial tumors. J Thorac Oncol 6: 606-613, 2011. 